\title{
Cocirculación de COVID-19 y dengue: un reto para el sistema
} de salud

\section{Co-circulation of COVID-19 and dengue: a challenge for the health system}

\section{Óscar Sosa-Hernández*}

Epidemiología, Hospital General de Zona 2, Instituto Mexicano del Seguro Social, San Luis, S.L.P. México

En nuestro país estamos viviendo la circulación simultánea de coronavirus 2 del síndrome respiratorio agudo grave (SARS-CoV-2), agente causal de la enfermedad por coronavirus 2019 (COVID-19) y los virus de dengue. Ambos presentan una gran similitud fisiopatológica y clínica, sin embargo, existen algunos datos que nos pueden orientar; ${ }^{1}$ por ejemplo, si el paciente presenta fiebre, dolor retroocular, vómito persistente y dolor abdominal podemos sospechar un dengue, pero si el paciente presenta fiebre, anosmia, ageusia y síntomas respiratorios tendremos que orientarnos hacia la COVID-19. ${ }^{2}$

La cocirculación de estos dos virus puede llevar a un retraso en el diagnóstico de cualquiera de los dos padecimientos, lo cual impacta directamente en la calidad de la atención del paciente. En términos epidemiológicos, el retraso en la detección de casos lleva a una tardía implementación de las medidas preventivas, lo cual puede generar una carga de trabajo para los servicios de salud. ${ }^{3}$

Nuestro sistema de salud debe continuar brindando atención a los pacientes con COVID-19 y al mismo tiempo tener la capacidad de detección de las arbovirosis, como el dengue, y ya tener listos protocolos de atención cuando inicie la temporada de influenza.

\section{Bibliografía}

1. Saavedra-Velasco M, Chiara-Chilet C, Pichardo-Rodríguez R, Grandez-Urbina A, Inga-Berrospi F. Coinfección entre dengue y COVID19: necesidad de abordaje en zonas endémicas. Rev Fac Cien Med Univ Nac Cordoba. 2020;77(1):52-4.

2. Nacher M, Douline M, Gaillet M, Flamand DR, Rousseau C, Mahdaoui C, et al. Simultaneous dengue and COVID-19 epidemics: Difficult days ahead? Trop Doct. 2020;50(3):270-2.

3. Ridwan R. COVID-19 and dengue: a deadly duo. Trop Doct. 2020; 50(3):270-2.

\section{Correspondencia:}

*Óscar Sosa-Hernández

E-mail: dr.oscar.sh@gmail.com

0016-3813/๑ 2020 Academia Nacional de Medicina de México, A.C. Publicado por Permanyer. Este es un artículo open access bajo la licencia CC BY-NC-ND (http://creativecommons.org/licenses/by-nc-nd/4.0/).
Gac Med Mex. 2021;157:221-221

Disponible en PubMed www.gacetamedicademexico.com 